\title{
Agrin-Induced Specializations Contain Cytoplasmic, Membrane, and Extracellular Matrix-Associated Components of the Postsynaptic Apparatus
}

\author{
Bruce G. Wallace \\ Department of Neurobiology, Stanford University School of Medicine, Stanford, California 94305
}

\begin{abstract}
The aims of the studies reported here were to determine the extent to which the specializations induced by agrin on cultured chick myotubes resemble the postsynaptic apparatus and examine how these specializations form. We found that agrin induces the formation of specializations at which at least 6 components of the postsynaptic apparatus are concentrated: one cytoplasmic component [a $43 \mathrm{kDa}$ acetylcholine receptor (AChR)-associated protein], 3 membrane components [AChRs and globular forms of acetylcholinesterase (AChE) and butyrylcholinesterase (BuChE)], and 2 extracellular matrix-associated proteins ( $A_{12}$ asymmetric $A C h E$ and a heparan sulfate proteoglycan). The accumulation of AChE and BuChE into agrin-induced aggregates occurred in the absence of any change in the amount, rate of synthesis, accumulation, and release, or molecular forms of either enzyme. Thus, agrin affects primarily the distribution of these components of the postsynaptic apparatus and not their metabolism.

Agrin-induced formation of AChR aggregates was not prevented by inhibition of protein synthesis, consistent with our previous results that agrin-induced accumulation of AChRs occurs by lateral migration. The accumulation of components of the extracellular matrix would seem less likely to occur by lateral migration and so might require release of newly synthesized proteins; indeed, formation of aggregates of heparan sulfate proteoglycan was prevented by inhibitors of protein synthesis. Thus, different components of the postsynaptic apparatus accumulate in agrin-induced specializations by different mechanisms.
\end{abstract}

The postsynaptic apparatus at the vertebrate skeletal neuromuscular junction is a complex structure, containing high concentrations of several extracellular matrix, membrane, and cy-

\footnotetext{
Received May 27, 1988; revised Aug. 18, 1988; accepted Sept. 13, 1988.

I am grateful to Dr. D. Fambrough (Johns Hopkins University), Dr. S. Froehner (Dartmouth Medical School), and Dr. A. Horwitz (University of Illinois) for generously providing monoclonal antibodies \#33 (anti-heparan sulfate proteoglycan), 120/C (anti-43 kDa AChR-associated protein), and CSAT (anti-integrin), respectively; to Dr. M. Smith (Stanford University School of Medicine) for providing agrin and immobilized anti-agrin antibodies; to Regina Williams for her excellent technical assistance; to Cecele Thomas for her unfailing secretarial support; and to Dr. U. J. McMahan (Stanford University School of Medicine) for his support and advice.

These studies were funded by National Institutes of Health Grant NS14506, the Muscular Dystrophy Association, the Isabelle Niemela Fund, the Weingart Foundation, the Wills Foundation, and a gift from Mr. Kcith Linden.

Correspondence should be addressed to Bruce $\mathrm{G}$. Wallace at the above address. Copyright (C) 1989 Society for Neuroscience 0270-6474/89/041294-09\$02.00/0
}

toplasmic components. We have previously shown that agrin, a protein extracted from the electric organ of Torpedo californica, induces the formation of specializations on the surface of cultured chick myotubes at which 3 components of the postsynaptic apparatus at the neuromuscular junction, acetylcholine receptors (AChRs), acetylcholinesterase (AChE), and butyrylcholinesterase (BuChE), are concentrated (Godfrey et al., 1984; Wallace et al., 1985; Wallace, 1986; Nitkin et al., 1987). The studies reported here were aimed at determining if agrin-induced specializations contain high concentrations of other components of the postsynaptic apparatus. We also sought to compare how different components accumulate.

Several molecular forms of $\mathrm{AChE}$ and $\mathrm{BuChE}$ are found in muscle: $G_{1}, G_{2}$, and $G_{4}$ globular forms, which are thought to be localized to the cytoplasm and plasma membrane, and $A_{4}, A_{8}$, and $A_{12}$ asymmetric forms, which are thought to be components of the extracellular matrix (Massoulie and Bon, 1982). The forms of $\mathrm{AChE}$ and $\mathrm{BuChE}$ concentrated at neuromuscular junctions varies among muscles and species (Massoulie and Bon, 1982), but a characteristic feature of neuromuscular junctions appears to be the accumulation of the $A_{12}$ asymmetric form of $\mathrm{AChE}$, which is localized extracellularly, predominantly in the synaptic basal lamina (Hall and Kelly, 1971; Betz and Sakmann, 1973; Hall, 1973; McMahan et al., 1978; Fernandez et al., 1984). It is of interest, therefore, to determine if agrin causes a change in the metabolism or molecular forms of AChE or BuChE in culturcd myotubes, if globular and/or asymmetric forms accumulate in agrin-induced specializations, and if agrin-induced cholinesterase (ChE) aggregates are associated with the myofiber's extracellular matrix.

The accumulation of AChRs into agrin-induced specializations on cultured myotubes occurs by lateral migration of receptors already in the plasma membrane (Godfrey et al., 1984; Wallace, 1988), as is the case, at least in part, for the accumulation of AChRs into synaptic sites on developing myofibers (Anderson and Cohen, 1977; Ziskind-Conhaim et al., 1984b; Role et al., 1985). It seems less likely that components of the extracellular matrix would be free to redistribute in response to agrin. Therefore, we examined whether one extracellular matrixassociated component of the postsynaptic apparatus that accumulates in agrin-induced aggregates, a heparan sulfate proteoglycan (Bayne et al., 1984), does so by redistribution of preexisting molecules.

We found that agrin-induced specializations contained both cytoplasmic, membrane, and extracellular matrix-associated components of the postsynaptic apparatus, that formation of $\mathrm{ChE}$ aggregates occurred without any overt change in $\mathrm{ChE}$ me- 
tabolism, and that different components appeared to accumulate by different mechanisms.

\section{Materials and Methods}

Chick myotube cultures. Myotube cultures were prepared from hindlimb muscles of 11- to 12-d-old White Leghorn chick embryos by the method of Fischbach (1972) with minor modifications (Godfrey et al., 1984; Wallace, 1986). Normal culture medium consisted of Eagle's minimum essential medium supplemented with $10 \%(\mathrm{vol} / \mathrm{vol})$ horse serum and $2 \%(\mathrm{vol} / \mathrm{vol})$ chick embryo extract (Wallace, 1986). In some experiments, cultures were transferred to defined medium consisting of a 1:1 mixture of Dulbecco's Modified Eagle's Medium/Nutrient mixture F-12 Ham (DME-F12, Sigma Chemical Co., St. Louis) supplemented with $0.8 \mathrm{~mm} \mathrm{CaCl}{ }_{2} 1 \mathrm{mg} / \mathrm{ml}$ BSA (RIA grade, Sigma), $20 \mu \mathrm{g} / \mathrm{ml}$ conalbumin (Type II, iron complex; Sigma), $100 \mathrm{U} / \mathrm{ml}$ penicillin, and 100 $\mu \mathrm{g} / \mathrm{ml}$ streptomycin. There was no obvious difference in the response of myotubes to agrin in this medium, except that the absence of horse serum and embryo extract reduced by 2-fold the amount of electric organ extract requircd to clicit a half-maximal response (see Wallace, 1986).

Agrin. Partially purified preparations of agrin, either a Cibacron extract $(84 \mathrm{U} / \mu \mathrm{g})$ or an agarose pool fraction $(114 \mathrm{U} / \mu \mathrm{g})$, were used in these studies. They were prepared from the electric organ of Torpedo californica as previously described (Nitkin et al., 1987), and the equivalent of 3-5 U was added to each culture.

Quantification of AChR aggregation. AChR and ChE aggregates were visualized and counted as previously described (Wallace, 1986). Briefly, myotube cultures were incubated with $2 \times 10^{-8} \mathrm{M}$ rhodamine- $\alpha$-bungarotoxin (Ravdin and Axelrod, 1977) in defined medium for $1 \mathrm{hr}$ at $37^{\circ} \mathrm{C}$. The cultures were washed twice with Puck's saline $G$ at room temperature, fixed for $10 \mathrm{~min}$ in ice-cold $1 \%$ paraformaldehyde dissolved in $90 \mathrm{~mm}$ sodium phosphate, $\mathrm{pH} \mathrm{7.2,} \mathrm{containing} 160 \mathrm{~mm}$ sucrose, rinscd twicc with Puck's salinc, and stained for ChE for $1 \frac{1 / 2}{\mathrm{hr}}$ at room temperature (Karnovsky, 1964). After staining, cultures were rinsed with Puck's saline, water, $50 \%$ ethanol, and $95 \%$ ethanol, and glass coverslips were mounted with a drop of glycerol. In experiments where the contributions of $\mathrm{AChE}$ and BuChE were determined pharmacologically, cultures were incubated prior to staining for $15 \mathrm{~min}$ with either $10^{-4} \mathrm{M}$ tetraisopropylpyrophosphoramide (iso-OMPA; Sigma), a specific inhibitor of BuChE, or $10^{-5} \mathrm{M}$ 1,5-bis-(4-allyldimethylammoniumphenyl) pentan-3-one dibromide (BW284c51; Sigma), an inhibitor selective for AChE. They were then stained as above either with $1.7 \mathrm{~mm}$ acetylthiocholine iodide as substrate in the presence of $10^{-4} \mathrm{M}$ iso-OMPA to demonstrate sites of $\mathrm{AChE}$ activity or with $1 \mathrm{~mm}$ butyrylthiocholine iodide as substrate in the presence of $10^{-5} \mathrm{M}$ BW284c51 to stain sites of BuChE activity.

Cultures were examined at a magnification of $320 \times$ with a Nikon microscope equipped with phase and fluorescence optics. The mean number of aggregates per $400 \mu \mathrm{m}$ myotube segment (or, for experiments in which myotubes were removed with CSAT antibody, per microscope field) was determined by counting 10 segments (or fields) in each of 3 cultures; only patches whose shortest axis was $>2 \mu \mathrm{m}$ were counted.

Inactivation of $C h E$. To ensure that the formation of $\mathrm{ChE}$ aggregates induced by electric organ extracts involved myotube $\mathrm{ChE}$ and was not due to $\mathrm{ChE}$ present in the culture medium or the extract itself, $2 \mathrm{mM}$ methane sulfonyl fluoride (MSF), an irreversible inhibitor of ChE (Kordas et al., 1975), was routinely added to the extracts and culture medium (Wallace, 1986).

ChE synthesis, accumulation, and release was determined by assaying $\mathrm{ChE}$ in culture homogenates and medium $24 \mathrm{hr}$ after inactivating all $\mathrm{ChE}$ in the cultures with diisopropylfluorophosphatc (DFP; Sancs ct al., 1984) and then incubating in MSF-treated culture medium with or without electric organ extracts.

To inactivate intracellular $\mathrm{ChE}$ selectively, cultures were rinsed twice for $5 \mathrm{~min}$ with a HEPES-buffered balanced salt solution consisting of $5.6 \mathrm{~mm}$ glucose, $0.44 \mathrm{mM} \mathrm{KH}_{2} \mathrm{PO}_{4}, 1.34 \mathrm{mM} \mathrm{Na}_{2} \mathrm{HPO}_{4}, 0.001 \%$ phenol red, $5.36 \mathrm{~mm} \mathrm{KCl}, 137 \mathrm{~mm} \mathrm{NaCl}, 1 \mathrm{~mm} \mathrm{MgCl}, 0.8 \mathrm{~mm} \mathrm{MgSO}_{4}, 1.3$ $\mathrm{mM} \mathrm{CaCl}_{2}, 25 \mathrm{~mm}$ HEPES, $\mathrm{pH} 7.4$, incubated for $3 \mathrm{~min}$ with $7 \times 10^{-5}$ м BW284c51 (to protect surface AChE) or $5 \times 10^{-6} \mathrm{M}$ neostigmine (to protect surface $A C h E$ and BuChE), incubated for 3 min with BW284c5 or neostigmine containing $10^{-4} \mathrm{M}$ DFP, rinsed twice for 2 min with BW284c51 or neostigmine, twice for $5 \mathrm{~min}$ with HEPES-buffered balanced salt solution, and rinsed once with Puck's saline (Rotundo, 1983; Ziskind-Conhaim et al., 1984a). Cultures were then either stained for sites of ChE activity or scraped into ice-cold extraction buffer $(25 \mu \mathrm{l} /$ $35 \mathrm{~mm}$ dish) consisting of $2 \mathrm{M} \mathrm{NaCl}, 2 \%$ (vol/vol) Triton X-100, 100 $\mathrm{mM}$ Tris- $\mathrm{Cl}, 2 \mathrm{mM}$ ethylenediamine tetraacetic acid (EDTA), $1 \mathrm{mg} / \mathrm{ml}$ bacitracin, $2 \mathrm{~mm}$ benzamidine, $20 \mu \mathrm{g} / \mathrm{ml}$ pepstatin, and $40 \mu \mathrm{g} / \mathrm{ml} \mathrm{leu}$ peptin, $\mathrm{pH}$ 7.0. Extracts were frozen and thawed 3 times, centrifuged for $5 \mathrm{~min}$ at $12,000 \times \mathrm{g}$, and the supernatants assayed for $\mathrm{ChE}$ activity or analyzed by sucrose gradient velocity sedimentation.

$C h E$ assay. ChE activity was measured spectrophotometrically by the method of Ellman et al. (1961). To assay AChE or BuChE activity selectively, extracts were preincubated for $10-20 \mathrm{~min}$ in reaction buffer containing the appropriate inhibitor $\left(10^{-5} \mathrm{M} \mathrm{BW} 284 \mathrm{c} 51\right.$ to inhibit $\mathrm{AChE}$ or $10^{-4} \mathrm{M}$ iso-OMPA to inhibit BuChE), and the reaction was initiated by adding the appropriate substrate ( $1 \mathrm{~mm}$ acetylthiocholine for AChE or $1 \mathrm{~mm}$ butyrylthiocholine for BuChE).

Protein assay. Protein was assayed by the method of Bradford (1976) with BSA as the standard.

Detergent treatment. To remove membrane and soluble cytoplasmic forms of ChE, cultures were rinsed with HEPES-buffered balanced salt solution, cooled on ice, gently agitated for $5 \mathrm{~min}$ in ice-cold buffer containing $0.5 \%$ (vol/vol) Triton X-100,300 mM sucrosc, $50 \mathrm{~mm} \mathrm{NaCl}$, $1 \mathrm{mM} \mathrm{MgCl}$, and $10 \mathrm{~mm}$ HEPES, pH 7.4 (Prives et al., 1982), rinsed twice with HEPES-buffered balanced salt solution, once with Puck's saline, and then either stained for sites of ChE activity or extracted for analysis of ChE forms. This protocol for detergent treatment has been shown to remove the plasma membrane, membranous organelles, and soluble cytoplasmic proteins but leave intact the cytoskeleton and myofibrillar apparatus (Prives et al., 1982).

CSAT treatment. To remove myotubes from the substratum, cultures were incubated for $6 \mathrm{hr}$ in normal culture medium containing 30-50 $\mu \mathrm{g} / \mathrm{ml}$ CSAT antibody (Neff et al., 1982; Horwitz et al., 1985).

Sucrose gradient velocity sedimentation. Velocity-sedimentation analysis of ChE activity was performed according to the general procedure of Martin and Ames (1961). Linear sucrose gradients (5-20\%) were prepared in $50 \mathrm{~mm}$ Tris-Cl, $\mathrm{pH} 7.0$, containing $1 \%(\mathrm{vol} / \mathrm{vol})$ Triton $\mathrm{X}-100,1 \mathrm{M} \mathrm{NaCl}$, and $1 \mathrm{~mm}$ EDTA. Bacterial alkaline phosphatase (6.1 $\mathrm{S})$, catalase $(11.3 \mathrm{~S}$ ), and $\beta$-galactosidase (16 S) were added to each sample as marker enzymes prior to sedimentation. Samples of $100 \mu \mathrm{l}$ were layered onto $4.4 \mathrm{ml}$ sucrose gradients in polyallomer tubes and centrifuged in the SW 60 rotor of a Beckman model L5-75 ultracentrifuge at $4^{\circ} \mathrm{C}$. Centrifugation lasted $8-16 \mathrm{hr}$ at $35,000-50,000 \mathrm{rpm}$, so that the product $\mathrm{rpm}^{2} \times \mathrm{hr}$ was approximately $2 \times 10^{10}$. The gradients were fractionated by drop collection from a pinhole made in the bottom of the tube. Aliquots of each fraction were assayed for $\mathrm{ChE}, \mathrm{AChE}$, or BuChE, alkaline phosphatase (Garen and Levinthal, 1960), catalase (Beers and Sizer, 1952), and $\beta$-galactosidase (Craven et al., 1965). A graph of the meniscus and the 3 marker enzymes against their sedimentation constants yielded a linear relationship from which the sedimentation constants of the forms of $\mathrm{AChE}$ and BuChE werc calculated. The molecular forms of AChE and BuChE were identified on the basis of their sedimentation coefficients (Massoulie and Bon, 1982).

Immunohistochemistry. To localize heparan sulfate proteoglycan together with AChRs, myotube cultures were labeled with rhodamine- $\alpha$ bungarotoxin, rinsed with Puck's saline, and incubated for $1 \mathrm{hr}$ at room temperature in $10 \mu \mathrm{g} / \mathrm{ml}$ anti-heparan sulfate proteoglycan monoclonal antibody \#33 (Bayne et al., 1984) dissolved in DME-F12 defined medium. The cultures were then rinsed for 15 min in 2 changes of Puck's saline, incubated for $1 \mathrm{hr}$ in fluorescein-conjugated goat anti-mouse IgG (Cappel Laboratories, Cochranville, PA) diluted 1:200 in Puck's saline containing $10 \%$ horse serum, rinsed for $15 \mathrm{~min}$ in 2 changes of Puck's saline, rinsed in $50 \%$ ethanol, $95 \%$ ethanol, and mounted under a glass coverslip in a drop of Citifluor mountant medium AF1 (City University, London). To visualize the distribution of $\mathrm{AChRs}$ and the $43 \mathrm{kDa} A \mathrm{ChR}-$ associated protein, myotube cultures were incubated with rhodamine$\alpha$-bungarotoxin, rinsed with Puck's saline, fixed and permeabilized with $95 \%$ ethanol for $5 \mathrm{~min}$ at $-20^{\circ} \mathrm{C}$, rinsed with Puck's saline, incubated for $1 \mathrm{hr}$ at room temperature with $1 \mu \mathrm{g} / \mathrm{ml}$ anti-43 $\mathrm{kDa}$ AChR-associated protein monoclonal antibody $120 / \mathrm{C}$ (Froehner et al., 1981) in Puck's saline containing $10 \%$ horse serum, rinsed with Puck's saline, incubated with fluorescein-conjugated goat anti-mouse IgG, rinsed, dehydrated, and mounted in Citifluor mountant medium AF1.

Immunoprecipitation. Aliquots of the Cibacron pool (62 units) were combined in $50 \mu \mathrm{l}$ of culture medium with $5 \mu \mathrm{l}$ of Sepharose beads to which normal mouse IgG or monoclonal antihodies from hybridoma supernatants or ascites fluid had been covalently coupled (Nitkin et al., 1987). After incubation for $2 \mathrm{hr}$ at $37^{\circ} \mathrm{C}$ with constant gentle agitation, 
Figure 1. Agrin does nol change the amount or molecular forms of $\mathrm{AChE}$ or BuChE. Sucrose gradient velocity sedimentation analysis of extracts of control $(O)$ and agrin-treated $(\triangle)$ chick myotube cultures grown in defined medium. Sedimentation was from right to left. The arrows in this and all other sucrose gradient profiles indicate the positions of marker enzymes (from left to right): $\beta$-galactosidase $(16 \mathrm{~S})$, catalase (1 1.3 S), and alkaline phosphatase (6.1 S). The molecular forms of AChE and BuChE were identified on the basis of soulie and Bon, 1982). Similar results were obtained for cultures grown in normal medium, except that under such conditions no $\mathrm{A}_{12} \mathrm{AChE}$ or $\mathrm{BuChE}$ was detected (data not shown). their sedimentation coefficients (Mas-

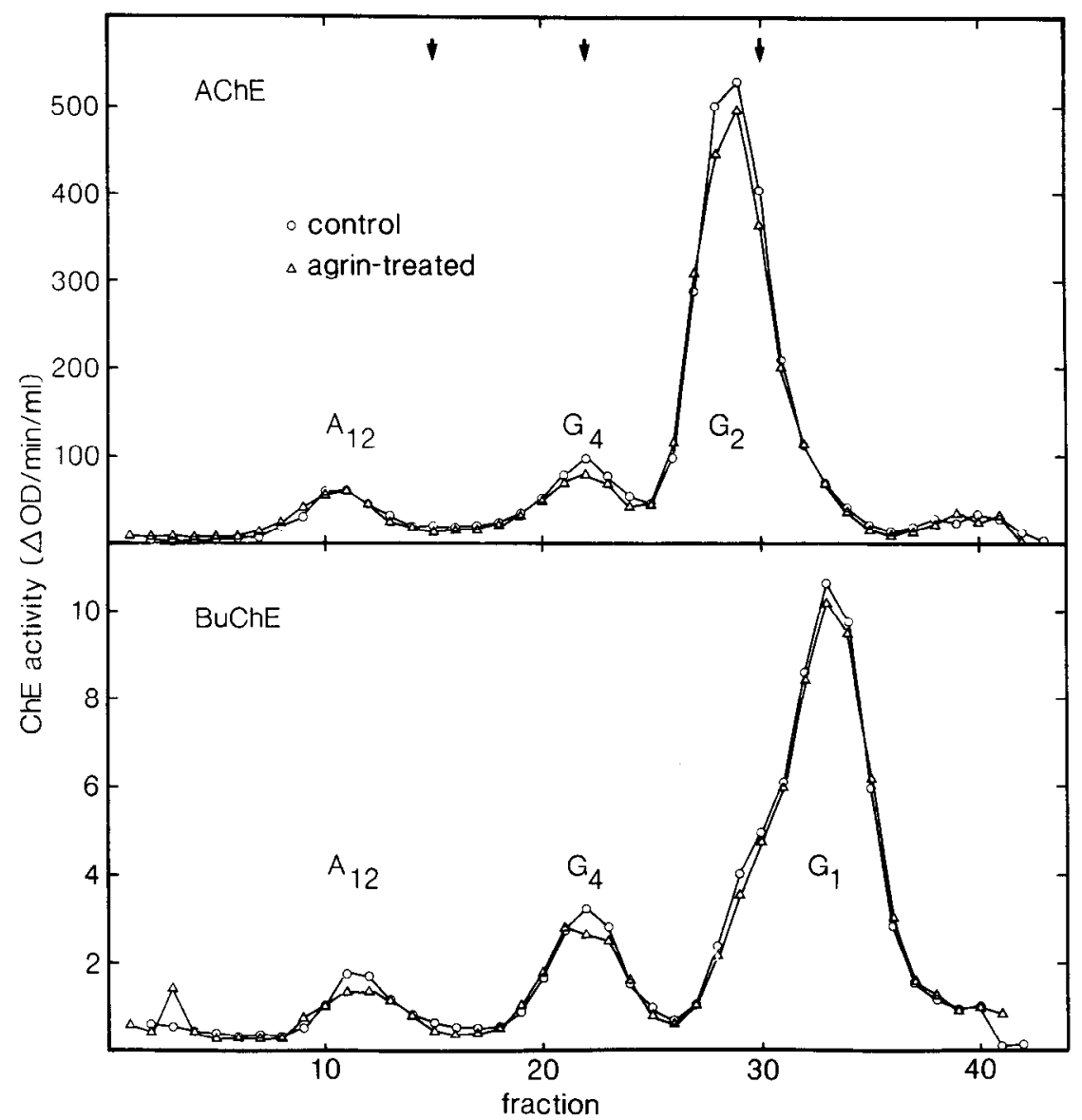

the beads were removed by centrifugation and the supernatants tested for residual aggregating activity.

Gel-filtration column chromatography. An aliquot of Cibacron pool was applied to a $94 \mathrm{ml}(120 \times 1 \mathrm{~cm})$ column of Sephacryl S-200 (Pharmacia Fine Chemicals, Piscataway, NJ) equilibrated and eluted with $0.2 \mathrm{M} \mathrm{NaHCO}_{3}, 0.5 \mathrm{M} \mathrm{NaCl}, 5 \%$ glycerol, $0.02 \%$ sodium azide, $\mathrm{pH} 9.0$. One-milliliter fractions were collected and assayed for aggregating activity.

\section{Results}

\section{Metabolism of ChE}

To determine whether agrin-induced formation of aggregates of ChE was associated with a change in ChE metabolism, the total amount of $\mathrm{ChE}$ in cultured myotubes, ChE synthesis and accumulation, and the release of $\mathrm{ChE}$ into the medium were assayed. To assess $\mathrm{ChE}$ synthesis, accumulation, and release, all $\mathrm{ChE}$ in the myotubes was inactivated with diisopropylfluorophosphate (DFP), the cultures were rinsed and returned to the incubator in fresh, esterase-free medium with or without agrin for $16 \mathrm{hr}$; then the medium and extracts of the cells were analyzed for ChE activity. Agrin induced the formation of AChR and $\mathrm{ChE}$ aggregates in such cultures as in those not exposed to DFP (data not shown). Adding agrin to cultures did not affect the level of ChE [agrin/control $=0.99 \pm 0.01$ (mean \pm SEM, $n=4)$ ], the amount of new ChE synthesized and accumulated in $16 \mathrm{hr}$ [agrin/control $=0.95 \pm 0.03$ (mean $\pm \mathrm{SEM}, n=3)$ ], or the amount of newly synthesized ChE that accumulated in the medium [agrin/control $=0.98 \pm 0.02$ (mean $\pm \mathrm{SEM}, n=$ 3)]. Thus, agrin-induced formation of $\mathrm{ChE}$ aggregates occurred in the absence of any overt changes in ChE metabolism.

Analysis of extracts of cultures incubated in normal culture medium by sucrose gradient velocity sedimentation revealed only globular forms of AChE and BuChE (data not shown). When myotubes were incubated overnight or longer in defined medium without horse serum or chick embryo extract, on the

Table 1. Total and surface $\mathrm{AChE}$ and BuChE in control and agrin-treated cultures

\begin{tabular}{lllll} 
& $\begin{array}{l}\text { Total AChE } \\
(5)\end{array}$ & $\begin{array}{l}\text { Surface AChE } \\
(10)\end{array}$ & $\begin{array}{l}\text { Total BuChE } \\
(3)\end{array}$ & $\begin{array}{l}\text { Surface BuChE } \\
\text { (3) }\end{array}$ \\
\hline Control & $4.47 \pm 0.25$ & $1.10 \pm 0.16$ & $0.15 \pm 0.05$ & $0.03 \pm 0.005$ \\
Agrin-treated & $4.55 \pm 0.25$ & $1.07 \pm 0.15$ & $0.18 \pm 0.06$ & $0.03 \pm 0.005$ \\
Agrin/control & $1.02 \pm 0.02$ & $1.02 \pm 0.05$ & $1.09 \pm 0.10$ & $1.04 \pm 0.02$
\end{tabular}

Data for control and agrin-treated entries are expressed as means $\pm \mathrm{SEM}$ of the $\Delta \mathrm{OD} / \mathrm{min} / \mathrm{mg}$ protein. Numbers in parentheses indicate number of experiments; in each experiment extracts of 3 cultures were combined and assayed in triplicate. Agrin/control is the mean \pm SEM of the ratios for each experiment. 


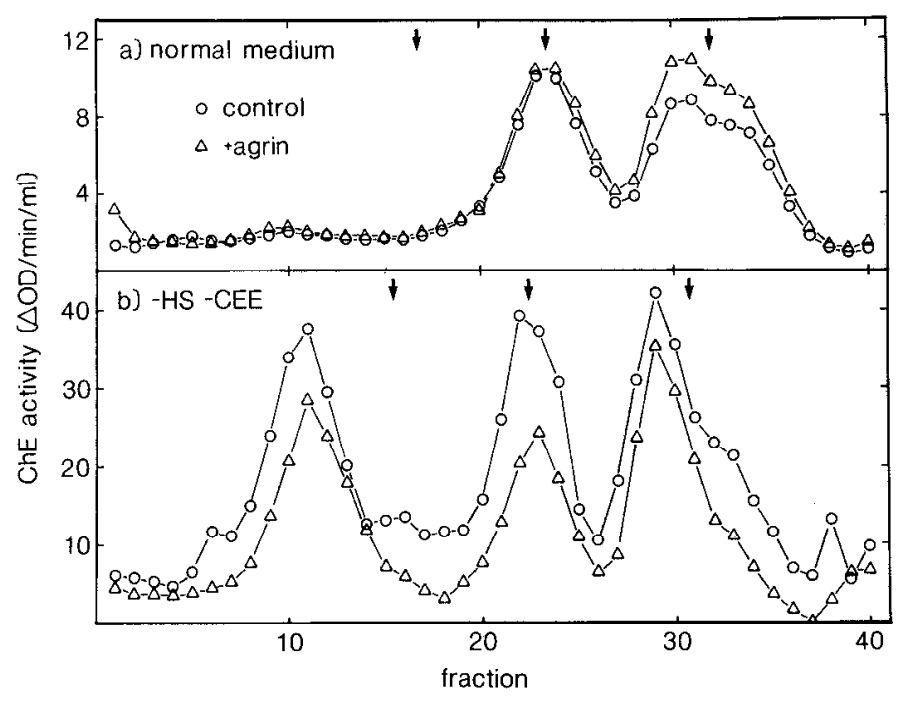

Figure 2. Agrin does not alter the amount or molecular forms of surface AChE. Sucrose gradient velocity sedimentation analysis of extracts of cultures incubated overnight in normal $(a)$ or defined $(b)$ medium with $(\triangle)$ or without $(O)$ agrin. Before extraction, cultures were treated with DFP in the presence of BW284c51 to inactivate intracellular enzyme. Similar results were obtained for BuChE (data not shown).

other hand, they contained, in addition to globular forms of $\mathrm{ChE}$, the $\mathrm{A}_{12}$ asymmetric form of both $\mathrm{AChE}$ and BuChE (Fig. 1). In either culture medium, adding agrin for $16 \mathrm{hr}$ did not change the amount or the proportion of the different molecular forms of AChE or BuChE (Table 1, Fig. 1).

\section{Agrin-induced ChE aggregates are on the cell surface}

Previous studies suggested that agrin-induced ChE aggregates were on the cell surface (Wallace, 1986). Since much of the ChE in cultured myotubes is intracellular (Rotundo, 1983), any agrininduced changes confined to $\mathrm{ChE}$ on the myotube surface might be difficult to detect when total cell $\mathrm{ChE}$ is analyzed. To examine the distribution and molecular forms of surface ChE selectively, cultures were treated to inactivate intracellular $\mathrm{ChE}$ and thus leave only surface ChE enzymatically active, then either stained histochemically for sites of ChE activity or extracted and analyzed by sucrose gradient velocity sedimentation. Surface ChE accounted for approximately $20 \%$ of the total ChE associated with cultured myotubes (Table 1). The number of agrin-induced ChE aggregates detected after inactivating intracellular enzyme was similar $[142 \pm 16 \%$ (mean $\pm \mathrm{SEM}, n=6)]$ to that in cultures stained by standard procedures, confirming that agrin-induced ChE aggregates are on the cell surface. Even under conditions in which only enzyme on the myotube surface was assayed, agrin did not cause a significant change in the amount or molecular forms of AChE or BuChE (Table 1, Fig. 2).

\section{Agrin-induced specializations contain globular and asymmetric forms of $A C h E$ and $B u C h E$}

Agrin induces the formation of $\mathrm{AChE}$ and $\mathrm{BuChE}$ aggregates on myotubes in normal culture medium (Wallace, 1986). In normal medium, myotubes contain only globular forms of $\mathrm{AChE}$ and BuChE; thus, under such conditions agrin-induced ChE aggregates must contain exclusively globular forms of $\mathrm{AChE}$ and $\mathrm{BuChE}$, presumably bound in the plasma membrane.

To determine if the $\mathrm{A}_{12}$ asymmetric forms of $\mathrm{AChE}$ and $\mathrm{BuChE}$ could also accumulate in agrin-induced specializations, as they

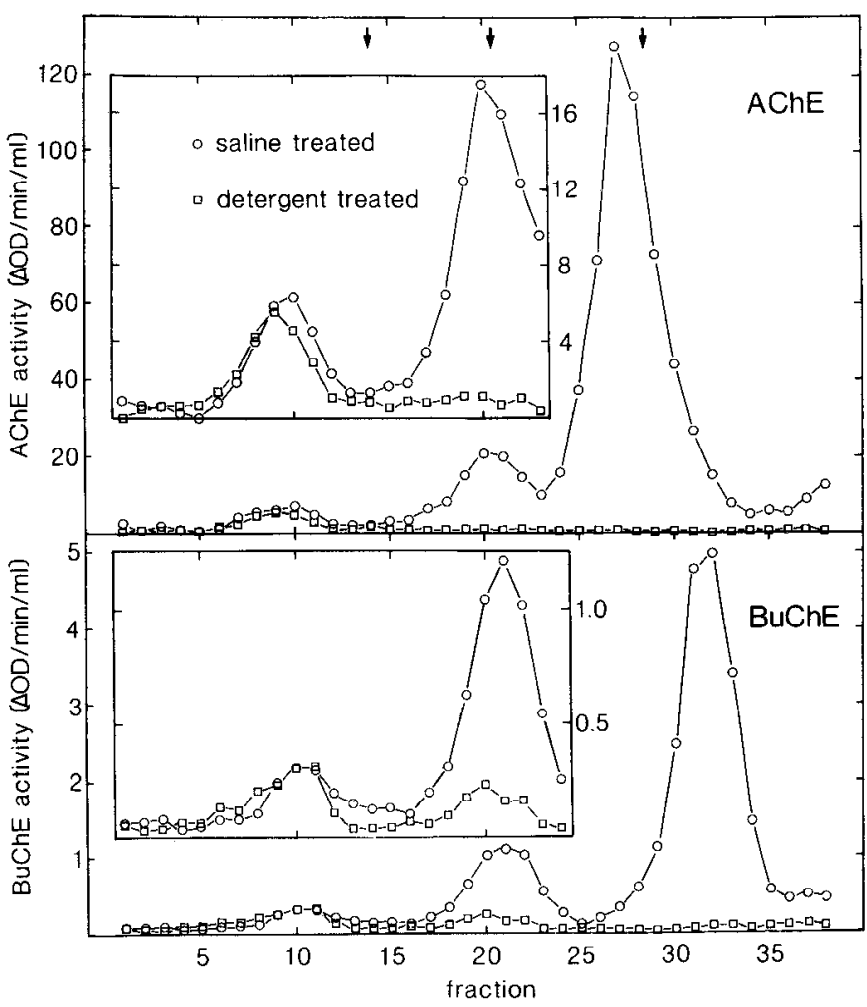

Figure 3. Detergent treatment removes globular forms of ChE. Sucrose gradient velocity sedimentation analysis of cultures incubated overnight in defined medium and treated with saline $(O)$ or detergent $(\square)$. Detergent-treated cultures contained only $\mathrm{A}_{12} \mathrm{AChE}$ (upper panel), they also contained $\mathrm{A}_{12} \mathrm{BuChE}$ and some less rapidly sedimenting form of $\mathrm{BuChE}$ as well (lower panel). Insets, Data for more rapidly sedimenting fractions replotted on an expanded ordinate.

do at neuromuscular junctions, control and agrin-treated cultures were treated with detergent to remove the soluble and membrane-bound globular forms of $\mathrm{AChE}$ and $\mathrm{BuChE}$, and then either stained histochemically or extracted for sucrose gradient velocity sedimentation analysis. As expected, no ChE activity was detected, either histochemically or on sucrose gradients of extracts of myotubes, in detergent-treated cultures grown in normal medium (data not shown), consistent with the finding that myotubes grown under these conditions contain only globular forms of ChE. Sucrose gradient analysis of extracts of cultures grown in the absence of serum and embryo extract, on the other hand, revealed that only $A_{12}$ AChE remained associated with the detergent-treated myotubes (Fig. 3); both $\mathrm{A}_{12}$ and some less rapidly sedimenting form of $\mathrm{BuChE}$ were consistently seen in such extracts (Fig. 3). No agrin-induced aggregates of BuChE were seen after detergent treatment; apparently, the level of $A_{12}$ $\mathrm{BuChE}$ was too low to be detected histochemically. However, agrin-induced aggregates of AChE were present following detergent treatment (Fig. 4); on average, detergent-treated cultures had $60 \pm 12 \%$ (mean $\pm \mathrm{SEM}, n=3$ ) as many agrin-induced $\mathrm{AChE}$ aggregates as nontreated cultures. Thus, agrin-induced aggregates contain the $A_{12}$ form of $A C h E$.

\section{$A_{I 2}$ asymmetric $A C h E$ accumulated at agrin-induced specializations is associated with the extracellular matrix}

To establish that agrin-induced aggregates of $\mathrm{A}_{12} \mathrm{AChE}$ were on the myotube surface, intracellular $\mathrm{ChE}$ was inactivated, the myotubes were treated with detergent to remove membrane and 
Figure 4. Agrin-induced ChE aggregates in control, detergent-treated, and CSAT-treated cultures. Phase micrographs of myotube segments $(a, b)$ or the culture substratum $(c)$ in cultures incubated overnight in defined medium containing agrin, treated as indicated, and then stained histochemically for sites of ChE activity. $a$, Saline-treated culture; $b$, detergent-treated culture; and $c$, substratum-associated ChE aggregates from a culture in which the myotubes were removed with CSAT antibody. Scale bar, $50 \mu \mathrm{m}$.
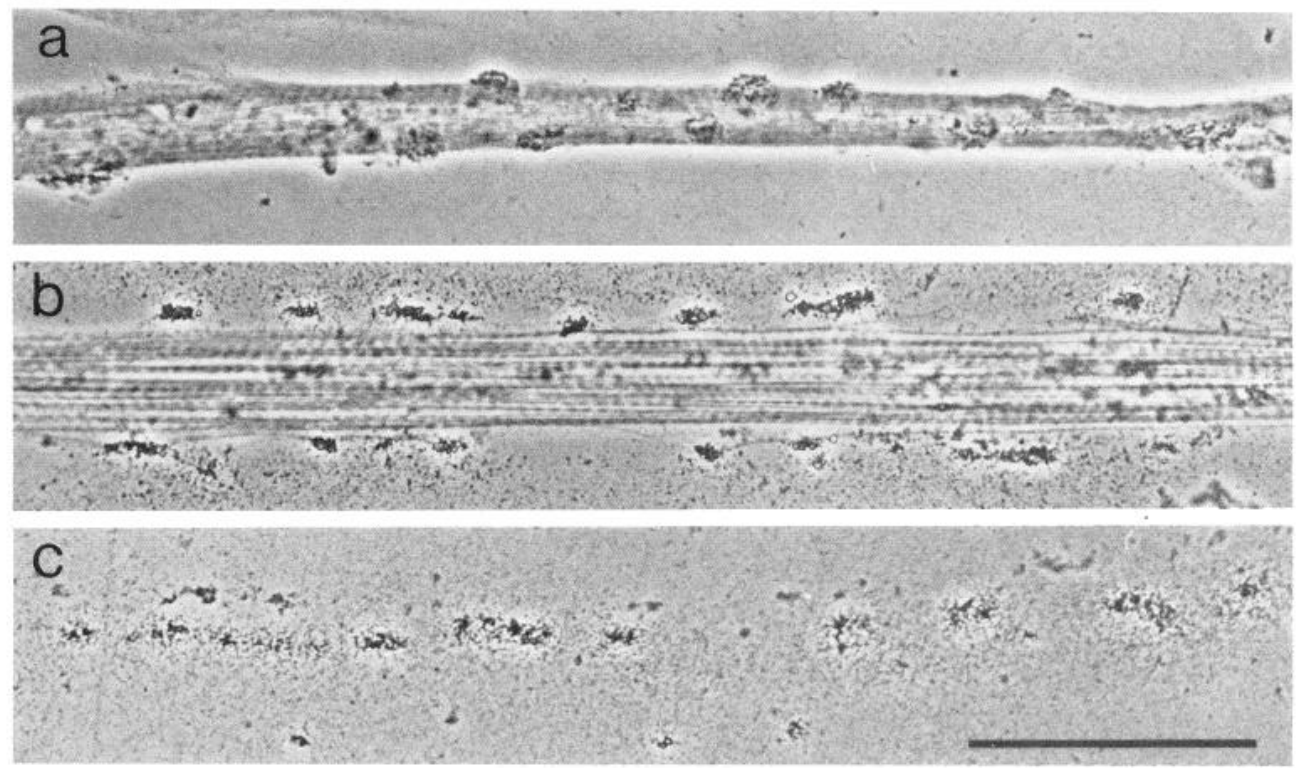

soluble enzyme, and the cultures were then stained histochemically or extracted and analyzed by sucrose gradient velocity sedimentation. AChE in extracts of such cultures was predominantly the $A_{12}$ form, as expected, and agrin-induced $\mathrm{AChE}$ aggregates (similar to those shown in Fig. $4 b$ ) could still be detected; on average, such cultures had $33 \pm 8 \%$ (mean \pm SEM, $n=9$ ) as many agrin-induced $\mathrm{AChE}$ aggregates as cultures stained by the standard protocol. Thus, when myotubes were grown in medium without horse serum and embryo extract, $\mathrm{A}_{12} \mathrm{AChE}$ on the cell surface was incorporated into agrin-induced specializations.

The resistance of the $\mathrm{A}_{12}$ form of $\mathrm{AChE}$ in cultured myotubes to detergent extraction is consistent with the hypothesis that it is associated with the myotube's basal lamina, as is the case at the neuromuscular junction. However, resistance to detergent extraction could also indicate association with the cytoskeleton. In order to provide additional evidence that the $\mathrm{A}_{12} \mathrm{AChE}$ detected in agrin-induced aggregates was associated with the myotube's basal lamina, myotubes were grown in medium without serum or embryo extract and treated with agrin for $16 \mathrm{hr}$ to induce the formation of $\mathrm{AChE}$ aggregates. The cultures were rinsed and incubated for an additional $6 \mathrm{hr}$ in medium supplemented with either saline or CSAT antibody, which binds to integrin and disrupts the interaction between myotubes and components of the extracellular matrix (Horwitz et al., 1985), causing the myotubes to detach from the collagen-coated surface of the culture dish (Neff et al., 1982). Cultures were then stained for AChE. As illustrated in Figure 4, following treatment with CSAT, aggregates of AChE were found on exposed portions of the substratum in agrin-treated cultures. The number of agrininduced AChE aggregates per microscope field in CSAT-treated cultures was $38 \pm 17 \%$ (mean $\pm \mathrm{SEM}, n=3)$ of that seen in cultures not treated with CSAT antibody. Aggregates of ChE were never seen between myotubes on the exposed substratum in cultures not treated with CSAT antibody. Therefore, $\mathrm{AChE}$ aggregates on the substratum of CSAT-treated cultures must originally have been associated with myotubes and have been left behind as the myotubes detached from the substratum, consistent with the hypothesis that $\mathrm{A}_{12} \mathrm{AChE}$ in such aggregates was associated with the extracellular matrix, rather than the myotube's cytoskeleton. Few such extracellular matrix-associated $\mathrm{AChE}$ aggregates were seen in agrin-treated cultures that had been grown in normal medium [CSAT-treated cultures had $7 \pm 3 \%$ (mean \pm SEM, $n=3$ ) as many agrin-induced AChE aggregates per microscope field as saline-treated cultures], consistent with the finding that myotubes grown in normal medium lack the $A_{12}$ form of AChE. Thus, agrin-induced specializations can contain both globular and asymmetric forms of AChE; at least some of the $A_{12}$ form, when it is present, appears to be associated with components of the extracellular matrix, as at the neuromuscular junction.

\section{Other components of the postsynaptic apparatus accumulate at agrin-induced specializations}

Two other components of the postsynaptic apparatus at the neuromuscular junction are a heparan sulfate proteoglycan identified by Bayne et al. (1984) and a $43 \mathrm{kDa}$ receptor-associated protein originally identified in AChR-containing extracts of electric organ (Froehner et al., 1981). As illustrated in Figure 5, specializations induced by extracts of electric organ contained high concentrations of both these proteins. Three lines of evidence indicate that agrin, which induces the accumulation of AChRs, AChE, and BuChE, also caused the accumulation of heparan sulfate proteoglycan and the $43 \mathrm{kDa}$ protein. First, as illustrated in Figure 6, the dose dependence for the formation of $43 \mathrm{kDa}$ and heparan sulfate proteoglycan aggregates was the same as that for AChR aggregates. Second, 5 different monoclonal antibodies, recognizing at least 4 different agrin epitopes, each immunoprecipitated all 5 aggregating activities (Fig. 7). Third, heparan sulfate proteoglycan- and $43 \mathrm{kDa}$ AChR-associated protein-aggregating activities comigrated on gel-filtration column chromatography with the AChR/ChE-aggregating activity (Fig. 8); as previously shown, the peaks of aggregating activity correspond to 150 and $95 \mathrm{kDa}$ polypeptides specifically immunoprecipitated by each of the anti-agrin monoclonal antibodies (Nitkin et al., 1987). Thus, our extracts of electric organ contain 2 active agrin polypeptides, of 150 and $95 \mathrm{kDa}$, each of which induces the formation of specializations on cultured myotubes at which at least 6 components of the postsynaptic apparatus are concentrated: 2 extracellular matrix molecules 

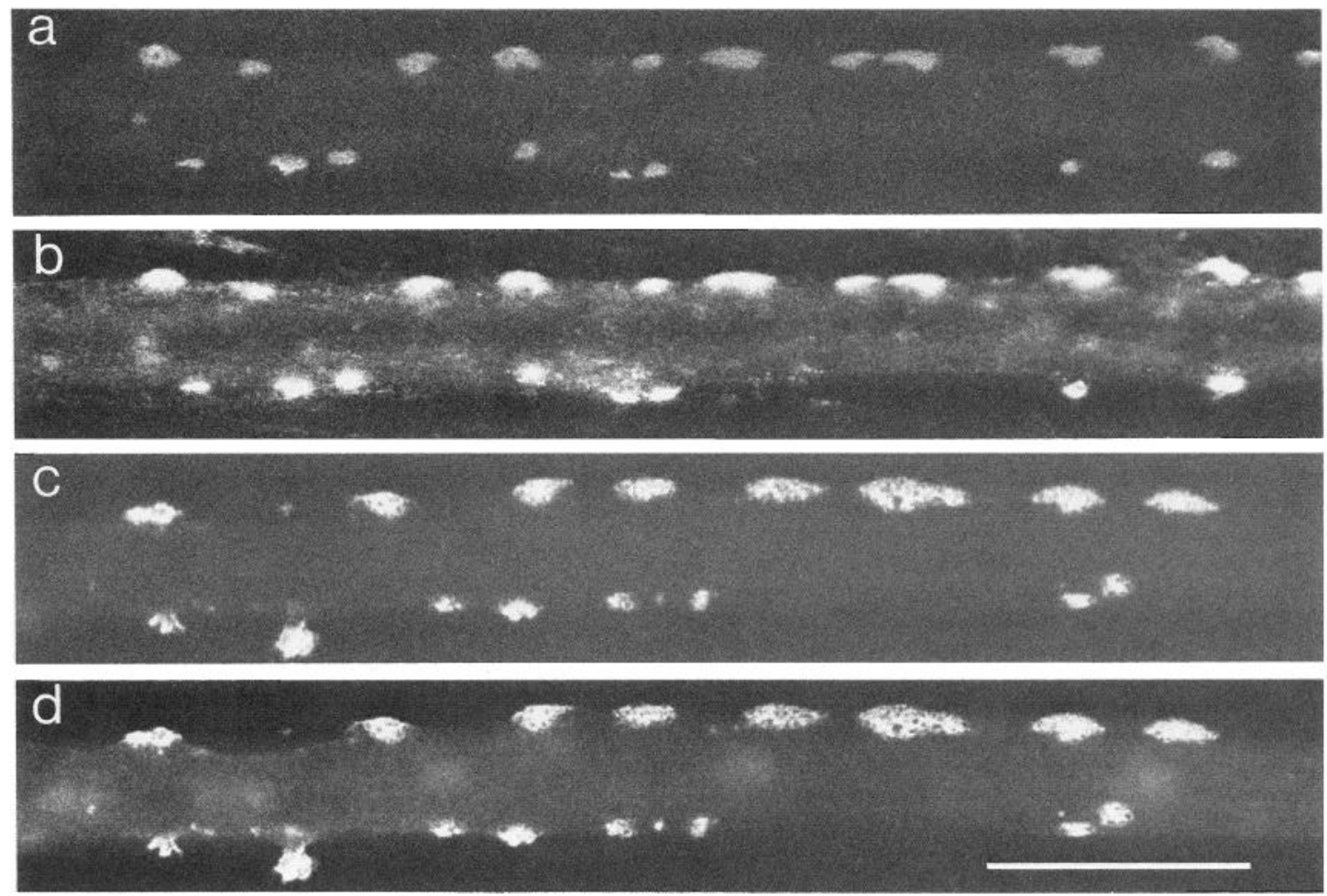

Figure 5. Agrin induces formation of aggregates of heparan sulfate proteoglycan and the $43 \mathrm{kDa}$ AChR-associated protein. Fluorescence micrographs of myotubes from cultures that were treated overnight with agrin and labeled with rhodamine- $\alpha$-bungarotoxin, antibodies to either heparan sulfate proteoglycan $(a, b)$ or the $43 \mathrm{kDa}$ AChR-associated protein $(c, d)$, and fluorescein-conjugated second antibody. $a$ and $c$, Rhodamine fluorescence to visualize $\mathrm{AChR}$ distribution; $b$ and $d$, fluorescein fluorescence to visualize the distribution of heparan sulfate proteoglycan $(b)$ or the $43 \mathrm{kDa} A C h R$ associated protein $(d)$. All 3 components of the postsynaptic apparatus accumulate in agrin-induced specializations. Scale bar, $50 \mu$ m.

(asymmetric $\mathrm{AChE}$ and a heparan sulfate proteoglycan), 3 membrane components (AChRs and globular forms of AChE and $\mathrm{BuChE}$ ), and 1 cytoplasmic component (the $43 \mathrm{kDa}$ receptorassociated protein).

\section{Mechanism of accumulation of heparan sulfate proteoglycan}

Components of the extracellular matrix are characterized by their insolubility in saline and detergent solutions. Accordingly, it seems unlikely that extracellular matrix-associated components, such as a heparan sulfate proteoglycan, would be free to accumulate at synaptic sites or in agrin-induced specializations by lateral migration. Therefore, one might predict that agrininduced accumulation of heparan sulfate proteoglycan would require insertion of new proteins into the myotube plasma membrane. To test this hypothesis, cultures were treated for various lengths of time with cycloheximide or puromycin and then exposed to agrin, and the formation of aggregates of AChRs and of heparan sulfate proteoglycan measured (Fig. 9). Cycloheximide and puromycin completely $(>98 \%)$ inhibited protein synthesis within $30 \mathrm{~min}$, as determined by the incorporation of ${ }^{35} \mathrm{~S}$-methionine into TCA-precipitable material. As previously reported (Wallace, 1988), inhibition of protein synthesis had little effect on AChR aggregation. On the other hand, $1 \mathrm{hr}$ pretreatment with cycloheximide or puromycin reduced the number of aggregates of heparan sulfate proteoglycan induced by agrin to $40 \%$ of control, and no increase was detected in myotubes pretreated for $3 \mathrm{hr}$, even though heparan sulfate proteoglycan was still readily detectable on the myotube surface. These results suggest that agrin-induced accumulation of heparan sulfate proteoglycan does not occur by lateral migration of molecules al- ready on the cell surface at the time agrin is added, but rather requires the release of newly synthesized proteins.

\section{Discussion}

When added to myotubes in culture, agrin appears to affect primarily the distribution of components of the postsynaptic apparatus, not their metabolism. This is most clearly the case for AChRs; agrin causes $\sim 50 \%$ of all AChRs on the surface of cultured chick myotubes to accumulate into aggregates without much change in AChR number or rate of degradation (Godfrey et al., 1984; Nitkin et al., 1987; Wallace, 1988). Likewise, agrin had no apparent effect on the metabolism of total or surface $\mathrm{ChE}$ in our cultured myotubes. However, we do not know what proportion of myotube $\mathrm{ChE}$ accumulates in agrin-induced specializations; the histochemical technique used to stain $\mathrm{ChE}$ and our method of counting ChE aggregates does not provide a quantitative estimate of the amount of $\mathrm{AChE}$ or BuChE in agrininduced aggregates, only the number of aggregates that could be detected. If agrin-induced specializations contain only a small fraction of the myotube's ChE, then changes in the synthesis, degradation, or molecular forms of that pool of ChE might have gone undetected. For the same reasons, although it is clear that asymmetric forms of $\mathrm{AChE}$ and globular forms of both $\mathrm{AChE}$ and $\mathrm{BuChE}$ accumulate on the myotube surface in agrin-induced specializations, we cannot estimate their relative concentrations.

Our evidence indicates that accumulation of components of the postsynaptic apparatus into agrin-induced aggregates can occur by at least 2 mechanisms. AChRs accumulate by lateral migration of receptors already in the myotube plasma mem- 


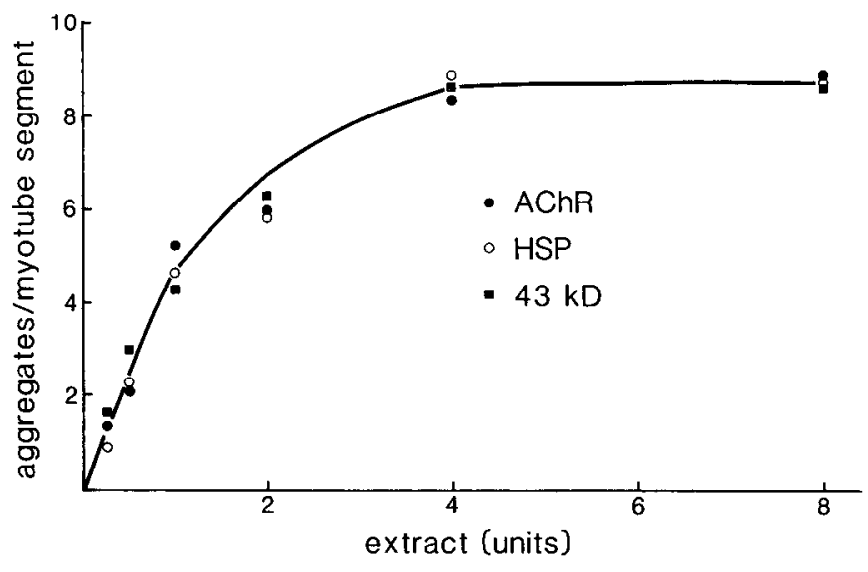

Figure 6. Dose dependence for agrin-induced formation of aggregates of AChRs, heparan sulfate proteoglycan, and $43 \mathrm{kDa}$ AChR-associated protein. Cultures were incubated overnight with varying amounts of partially purified agrin and labeled with rhodamine- $\alpha$-bungarotoxin and antibodies to either heparan sulfate proteoglycan or the $43 \mathrm{kDa} A C h R-$ associated protein. As the amount of extract was increased, the number of aggregates increased and then reached a plateau. The dose dependence for formation of heparan sulfate proteoglycan (O) and $43 \mathrm{kDa}$ AChRassociated protein aggregates $(\square)$ was the same as that for AChR aggregates $(\bullet)$. Each data point is the mean of triplicate determinations.

brane at the time agrin is added (Godfrey et al., 1984; Wallace, 1988). Moreover, the accumulation of AChRs is not blocked by inhibitors of protein synthesis (Wallace, 1988; Fig. 9). The agrin-induced accumulation of heparan sulfate proteoglycan, on the other hand, is blocked by inhibitors of protein synthesis. Preincubating myotubes for $1 \mathrm{hr}$ with cycloheximide or puromycin caused a $40 \%$ reduction in the number of agrin-induced heparan sulfate proteoglycan aggregates, and preincubation for $3 \mathrm{hr}$ blocked formation of heparan sulfate proteoglycan aggregates completely. Cycloheximide and puromycin completely inhibited protein synthesis within $30 \mathrm{~min}$; however, it requires 2-3 hr for plasma membrane or secreted proteins, such as AChRs and $\mathrm{AChE}$, to reach the surface of cultured myotubes after they are synthesized (Rotundo and Fambrough, 1980). Assuming the intracellular transport of heparan sulfate proteoglycan occurs by a similar mechanism, the time course of inhibition of agrininduced heparan sulfate proteoglycan aggregate formation by cycloheximide and puromycin parallels that of the depletion of intracellular heparan sulfate proteoglycan pools. Thus, aggregates of heparan sulfate proteoglycan do not appear to form by lateral migration of preexisting molecules but by either local immobilization of molecules as they are released or localization of release sites themselves. This might come about, for example, by agrin causing the accumulation by lateral migration of molecules in the myotube plasma membrane that bind heparan sulfate proteoglycan or that determine where along the plasma membrane vesicles laden with components of the postsynaptic apparatus fuse and relcase their contents onto the myotube surface. It would be interesting to determine how the accumulation of other components of the postsynaptic apparatus is affected by protein synthesis inhibitors. Unfortunately, in preliminary experiments we found we could not reliably assess the effect of protein synthesis inhibitors on AChE or BuChE accumulation because of the difficulty in resolving agrin-induced $\mathrm{ChE}$ aggregates from background staining after short incubations with agrin (see Wallace, 1988).

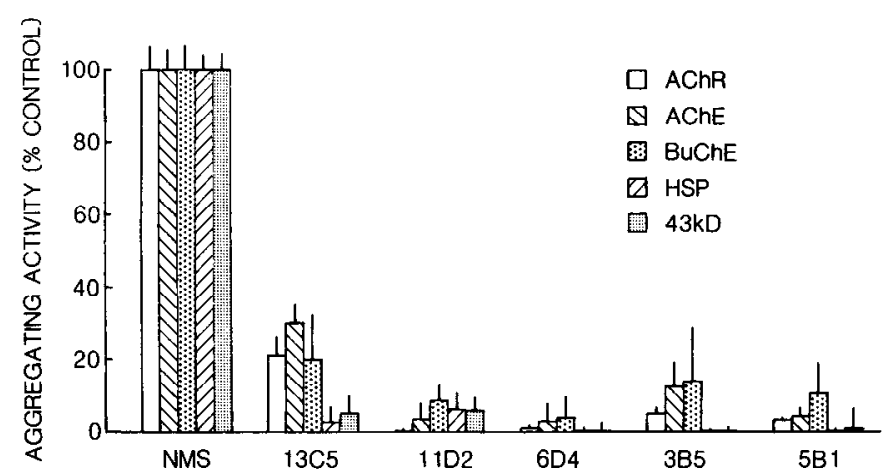

Figure 7. Anti-agrin antibodies immunoprecipitate all 5 aggregating activities. Aliquots of a Cibacron pool extract of electric organ were incubated with Sepharose beads to which either normal mouse serum IgG (NMS) or 1 of 5 different monoclonal antibodies, recognizing at least 4 different epitopes, had been coupled (Nitkin et al., 1987; Reist et al., 1987). The amount of aggregating activity that remained in the supernatant after the beads were removed by centrifugation was measured. Results are plotted as means $\perp$ SEM for triplicate determinations.

Although many factors have been shown to cause formation of aggregates of AChRs and AChE on cultured myotubes (for review, see Godfrey et al., 1984; Nitkin et al., 1987; Wallace, 1988), several lines of evidence are consistent with the hypothesis that agrin, or a closely related protein, is released by axon terminals to trigger the formation of $\mathrm{AChR} / \mathrm{AChE}$ aggregates at developing neuromuscular junctions. For example, motor neurons in both embryos and adults contain molecules that cause the formation of $\mathrm{AChR}$ and $\mathrm{AChE}$ aggregates on cultured myotubes and these $\Lambda \mathrm{ChR} / \Lambda \mathrm{ChE}$-aggregating molecules are recognized by anti-agrin monoclonal antibodies (Magill-Solc and McMahan, 1988). Moreover, antibodies to agrin bind to molecules concentrated in the Golgi apparatus of spinal motoneurons and in the basal lamina in the synaptic cleft at adult neuromuscular junctions (Smith et al., 1987; Reist et al., 1987; Magill-Solc and McMahan, 1988). If axon terminals release molecules similar to agrin, then our finding that $\mathrm{A}_{12} \mathrm{AChE}$ and heparan sulfate proteoglycan, 2 components of the synaptic basal lamina at the neuromuscular junction, accumulate at agrininduced specializations may account for the observation that the first place basal lamina is visible on developing myotubes is at sites of synaptic contact (Dennis, 1981). Moreover, the early deposition of basal lamina at synaptic sites might function to provide a scaffold to which agrin, released from the axon terminal, could bind and thus more effectively induce further differentiation of the postsynaptic apparatus (Nitkin et al., 1987). It remains to be determined whether myotubes in our cultures do, in fact, assemble a recognizable basal lamina sheath and, if so, whether $\mathrm{A}_{12} \mathrm{AChE}$ and heparan sulfate proteoglycan accumulate by virtue of being incorporated into it or simply by adhering to the collagen substrate.

It has been suggested that deposition of heparan sulfate protcoglycan is an early step in AChR aggregation at developing synapses (Anderson and Fambrough, 1983; Bayne et al., 1984; Anderson, 1986). However, it is clear from our results that formation of aggregates of heparan sulfate proteoglycan is not prerequisite for AChR aggregation; in myotubes pretreated with inhibitors of protein synthesis, no aggregates of heparan sulfate proteoglycan were detected, yet agrin-induced formation of AChR aggregates. Likewise, axon terminals can induce AChR aggregation on myotubes deficient in heparan sulfate proteogly- 


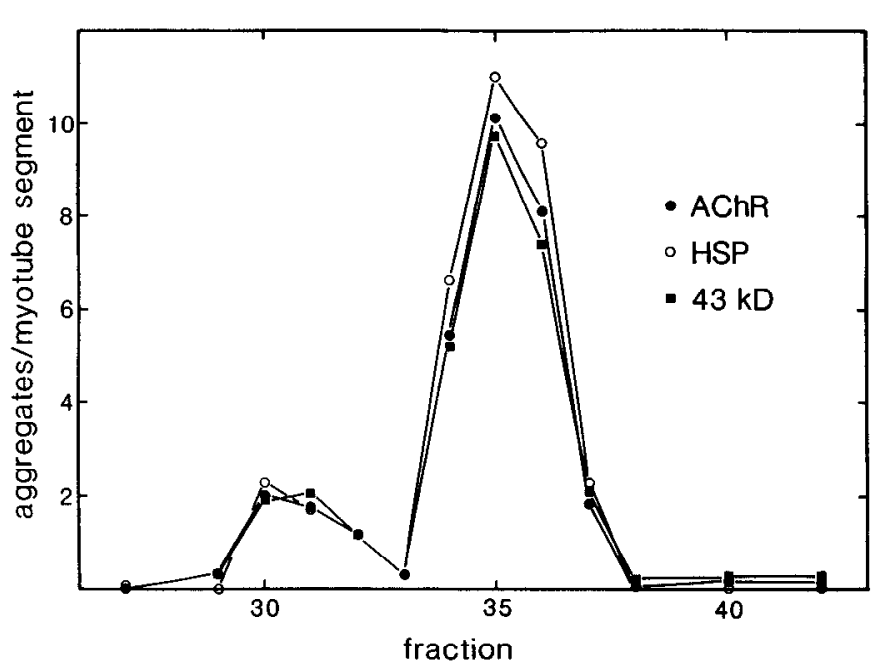

Figure 8. Heparan sulfate proteoglycan-, $43 \mathrm{kDa}$ AChR-associated protein-, and AChR/ChE-aggregating activities comigrate on gel-filtration chromatography. An aliquot of Cibacron pool extract of electric organ was applied to a Sephacryl S-200 gel-filtration column. Each fraction was analyzed for $\mathrm{AChR} / \mathrm{ChE}-(\bullet)$, heparan sulfate proteoglycan$(O)$, and $43 \mathrm{kDa}$ AChR-associated protein-aggregating activity (D). Each data point is the mean of triplicate determinations.

can synthesis (Gordon et al., 1988). On the other hand, heparan sulfate proteoglycan might play a role in the accumulation of other components of the postsynaptic apparatus. For example, $A_{12}$ asymmetric $A C h E$ has been shown to bind specifically to heparan sulfate proteoglycan and $\mathrm{AChE}$ concentrated at neuromuscular junctions can be solubilized with heparin or heparan sulfate (Inestrosa et al., 1982; Brandan et al., 1985; Brandan and Inestrosa, 1986).

The results of the experiments described in this report demonstrate that agrin triggers the formation of specializations that contain at least 6 components of the postsynaptic apparatus. However, the level to which some of the components-for example, AChE-accumulate at agrin-induced specializations appears to be lower than at the neuromuscular junction (Wallace, 1986, 1988). Likewise, agrin-induced AChR aggregation occurs in the absence of any significant change in the number of AChRs (Godfrey et al., 1984), while it has been reported that the rate of AChR synthesis increases at developing neuromuscular junctions (Role et al., 1985). Thus, although agrin-induced specializations may contain many or all of the components of the postsynaptic apparatus, additional signals-such as electromechanical activity (Dennis, 1981), ARIA (Usdin and Fischbach, 1986), or calcitonin gene-related peptide (New and Mudge, 1986)-would appear to be required to mimic more precisely events at developing neuromuscular junctions.

\section{References}

Anderson, M. J. (1986) Nerve-induced remodeling of muscle basal lamina during synaptogenesis. J. Cell Biol. 102: 863-877.

Anderson, M. J., and M. W. Cohen (1977) Nerve-induced and spontaneous redistribution of acetylcholine receptors on cultured muscle cells. J. Physiol. (Lond). 268: 757-773.

Anderson, M. J., and D. M. Fambrough (1983) Aggregates of acetylcholine receptors are associated with plaques of a basal lamina heparan sulfate proteoglycan on the surface of skeletal muscle fibers. J. Cell Biol. 97: 1396-1411.

Bayne, E. K., M. J. Anderson, and D. M. Fambrough (1984) Extracellular matrix organization in developing muscle: Correlation with acetylcholine receptor aggregates. J. Cell Biol. 99: 1486-1501.

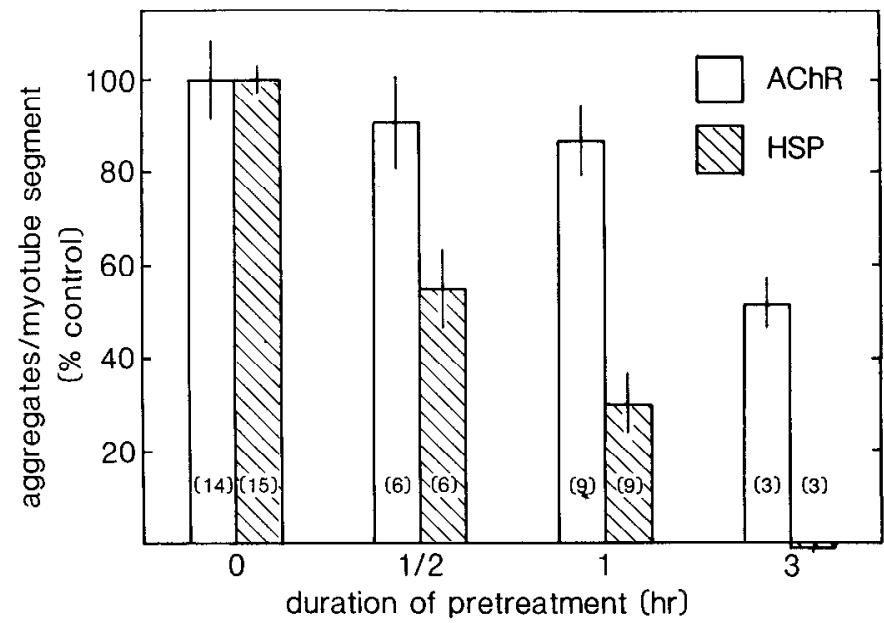

Figure 9. Inhibitors of protein synthesis block agrin-induced formation of heparan sulfate proteoglycan aggregates but not AChR aggregation. Cultures were treated with $0.1 \mathrm{mg} / \mathrm{ml}$ cycloheximide or puromycin for $0,1 / 2,1$, or $3 \mathrm{hr}$, agrin was added, and the cultures were incubated for an additional $6 \mathrm{hr}$. The cultures were then rinsed and labeled with rhodamine- $\alpha$-bungarotoxin and anti-heparan sulfate proteoglycan antibodies. The agrin-induced increase in the number of aggregates/myotuhe segment is plotted for AChRs (open columns) and heparan sulfate proteoglycan (cross-hatched columns). Data are expressed as means \pm SEM, with the number of observations indicated within the columns.

Beers, R. F., Jr., and I. W. Sizer (1952) A spectrophotometric method for measuring the breakdown of hydrogen peroxide by catalase. $J$. Biol. Chem. 195: 133-140.

Betz, W., and B. Sakmann (1973) Effect of proteolytic enzymes on function and structure of frog neuromuscular junctions. J. Physiol. (Lond.) 230: 673-688.

Bradford, M. M. (1976) A rapid and sensitive method for the quantitation of microgram quantities of protein utilizing the principle of protein-dye binding. Anal. Biochem. 72: 248-254.

Brandan, E. M., and N. C. Inestrosa (1986) The synaptic form of acetylcholincstcrase binds to cell surface heparan sulfate protcoglycans. J. Neurosci. Res. 15: 185-196.

Brandan, E., M. Maldonado, J. Garrido, and N. C. Inestrosa (1985) Anchorage of collagen-tailed acetylcholinesterase to the extracellular matrix is mediated by heparan sulfate proteoglycans. J. Cell Biol. 101: 985-992.

Craven, G. R., E. Steers, Jr., and C. B. Anfinsen (1965) Purification, composition, and molecular weight of the $\beta$-galactosidase of Escherichia coli K12. J. Biol. Chem. 240: 2468-2477.

Dennis, M. J. (1981) Development of the neuromuscular junction: Inductive interactions between cells. Annu. Rev. Neurosci. 4: 43-68.

Ellman, G. L., K. D. Courtney, V. Andres, Jr., and R. M. Featherstone (1961) A new and rapid colourimetric determination of acetylcholinesterase activity. Biochem. Pharmacol. 7: 88-95.

Fcrnandez, L. H., N. C. Inestrosa, and J. R. Stiles (1984) Subcellular localization of acetylcholinesterase molecular forms in endplate regions of adult mammalian skeletal muscle. Neurochem. Res. 9: 12111230 .

Fischbach, G. D. (1972) Synapse formation between dissociated nerve and muscle cells in low density cell cultures. Dev. Biol. 28: 407-429.

Froehner, S. C., V. Gulbrandsen, C. Hyman, A. Y. Yeng, R. R. Neubig, and J. B. Cohen (1981) Immunofluorescence localization at the mammalian neuromuscular junction of the $M_{r} 43,000$ protein of Torpedo postsynaptic membranes. Proc. Natl. Acad. Sci. USA 78: 5230 5234 .

Garen, A., and C. Levinthal (1960) A fine-structure genetic and chemical study of the enzyme alkaline phosphatase of $E$. coli. I. Purification and characterization of alkaline phosphatase. Biochim. Biophys. Acta 38: $470-483$.

Godfrey, E. W., R. M. Nitkin, B. G. Wallace, L. L. Rubin, and U. J. McMahan (1984) Components of Torpedo electric organ and muscle 
that cause aggregation of acetylcholinc reccptors on cultured muscle cells. J. Cell Biol. 99: 615-627.

Gordon, H., M. T. Lupa, and Z. W. Hall (1988) A muscle cell variant defective in GAG biosynthesis is also defective in spontancous clustering of acetylcholine receptors. J. Cell. Biochem. (Suppl.) 12C: 351.

Hall, Z. W. (1973) Multiple forms of acetylcholinesterase and their distribution in endplate and non-endplate regions of rat diaphragm muscle. J. Neurobiol. 4: 343-361.

Hall, Z. W. and R. B. Kelly (1971) Enzymatic detachment of endplate acetylcholinesterase from muscle. Nature [New Biol.] 232: 62-63.

Horwitz, A., K. Duggan, R. Greggs, C. Decker, and C. Buck (1985) The cell substrate attachment (CSAT) antigen has properties of a receptor for laminin and fibronectin. J. Cell Biol. 101: 2134-2144.

Inestrosa, N. C., L. Silberstein, and Z. W. Hall (1982) Association of the synaptic form of acetylcholincstcrase with cxtraccllular matrix in cultured mouse muscle cells. Cell 29: 71-79.

Karnovsky, M. J. (1964) The localization of cholinesterase activity in rat cardiac muscle by electron microscopy. J. Cell Biol. 23: 217-232.

Kordas, M., M. Brzin, and Z. Majcen (1975) A comparison of the effect of cholinesterase inhibitors on end-plate current and on cholinesterase activity in frog muscle. Neuropharmacology 14: 791-800.

Magill-Solc, C., and U. J. McMahan (1988) Motor neurons contain agrin-like molecules. J. Cell Biol. 107: 1825-1833.

Martin, R. G., and B. N. Ames (1961) A method for determining the sedimentation behavior of enzymes: Application to protein mixtures. J. Biol. Chem. 236: 1372-1379.

Massoulie, J., and S. Bon (1982) The molecular forms of cholinesterase and acetylcholinesterase in vertebrates. Annu. Rev. Neurosci. 5: 57106.

McMahan, U. J., J. R. Sanes, and L. M. Marshall (1978) Cholinesterase is associated with the basal lamina at the neuromuscular junction. Nature 271: 172-174.

Neff, N. T., C. Lowrey, C. Decker, A. Tovar, C. Damsky, C. Buck, and A. F. Horwitz (1982) A monoclonal antibody detaches embryonic skeletal muscle from extracellular matrices. J. Cell Biol. 95: 654-666.

New, H. V., and A. W. Mudge (1986) Calcitonin gene-related peptide regulates muscle acetylcholine receptor synthesis. Nature 323: 809811.

Nitkin, R. M., M. A. Smith, C. Magill, J. R. Fallon, Y.-M. M. Yao, B. G. Wallace, and U. J. McMahan (1987) Identification of agrin, a synaptic organizing protein from Torpedo electric organ. J. Cell Biol. 105: 2471-2478.

Prives, J., A. B. Fulton, S. Pcnman, M. P. Danicls, and C. N. Christian (1982) Interaction of the cytoskeletal framework with acetylcholine receptor on the surface of embryonic muscle cells in culture. J. Cell Biol. 92: 231-236.
Ravdin, P., and D. Axclrod (1977) Fluorescent tetramethyl rhodamine derivatives of $\alpha$-bungarotoxin: Preparation, separation, and characterization. Anal. Biochem. 80: 585-592.

Reist, N. E., C. Magill, and U. J. McMahan (1987) Agrin-like molecules at synaptic sites in normal, denervated and damaged skeletal muscles. J. Cell Biol. 105: 2457-2469.

Role, L. W., V. R. Matossian, R. J. O'Brien, and G. D. Fischbach (1985) On the mechanism of acetylcholine receptor accumulation at newly formed synapses on chick myotubes. J. Neurosci. 5: 2197-2204.

Rotundo, R. L. (1983) Acetylcholinesterase biosynthesis and transport in tissue culture. Methods Enzymol. 96: 353-367.

Rotundo, R. L., and D. M. Fambrough (1980) Synthesis, transport and fate of acetylcholinesterase in cultured chick embryo muscle cells. Cell 22: 583-594.

Sancs, J. R., D. H. Feldman, J. M. Cheney, and J. C. Lawrence, Jr. (1984) Brain extract induces synaptic characteristics in the basal lamina of cultured myotubes. J. Neurosci. 4: 464-473.

Smith, M. A., Y.-M. Yao, N. E. Reist, C. Magill, B. G. Wallace, and U. J. McMahan (1987) Identification of agrin in electric organ extracts and localization of agrin-like molecules in muscle and central nervous system. J. Exp. Biol. 132: 223-230.

Usdin, T. B., and G. D. Fischbach (1986) Purification and characterization of a polypeptide from chick brain that promotes the accumulation of acetylcholine receptors in chick myotubes. J. Cell Biol. 103: 493-507.

Wallace, B. G. (1986) Aggregating factor from Torpedo electric organ induces patches containing acetylcholine receptors, acetylcholinesterase, and butyrylcholinesterase on cultured myotubes. J. Cell Biol. 102: 783-794.

Wallace, B. G. (1988) Regulation of agrin-induced acetylcholine receptor aggregation by $\mathrm{Ca}^{2+}$ and phorbol ester. J. Cell Biol, 107: 267278 .

Wallace, B. G., R. M. Nitkin, N. E. Reist, J. R. Fallon, N. N. Moayeri, and U. J. McMahan (1985) Aggregates of acetylcholinesterase induced by acetylcholine-receptor aggregating factor. Nature $315: 574$ 577.

Ziskind-Conhaim, L., N. C. Inestrosa, and Z. W. Hall (1984a) Acetylcholinesterase is functional in embryonic rat muscle before its accumulation at the sites of nerve-muscle contact. Dev. Biol. 103:369377.

Ziskind-Conhaim, L., I. Geffen, and Z. W. Hall (1984b) Redistribution of acetylcholine receptors on developing rat myotubes. J. Neurosci. 4: $2346-2349$. 